\title{
Vitamin E intake and risk of stroke: a meta-analysis
}

\author{
Pengfei Cheng ${ }^{1,2 *}$, Lihua Wang ${ }^{1}$, Shujun Ning ${ }^{1}$, Zichun Liu $^{2}$, Hao Lin ${ }^{1}$, Shuli Chen ${ }^{3}$ and Jiaying Zhu ${ }^{1}$ \\ ${ }^{1}$ Department of Neurology, The First Affiliated Hospital of Jiamusi University, 154002 Jiamusi, Heilongjiang Province, People's \\ Republic of China \\ ${ }^{2}$ Department of Histology and Embryology, School of Basic Medical Sciences, Jiamusi University, 154002 Jiamusi, Heilongiang \\ Province, People's Republic of China \\ ${ }^{3}$ Department of Cardiology, The First Affiliated Hospital of Jiamusi University, 154002 Jiamusi, Heilongjiang Province, People's \\ Republic of China
}

(Submitted 1 March 2018 - Final revision received 18 July 2018 - Accepted 22 August 2018)

\section{Abstract}

Findings from observational studies on the associations between vitamin $\mathrm{E}$ intake and stroke risk remain controversial, and the dose-response relationship between vitamin $\mathrm{E}$ intake and risk of stroke remains to be determined. We conducted a meta-analysis of prospective studies aiming to clarify the relationships between vitamin $\mathrm{E}$ intake and risk of stroke. Relevant studies were identified by searching online databases through to June 2018. We computed summary relative risks (RR) with corresponding 95\% CI. Among 3156 articles retrieved from online databases and relevant bibliographies, nine studies involving 3284 events and 220371 participants were included in the final analyses. High dietary vitamin $\mathrm{E}$ intake was inversely associated with the risk of overall stroke ( $\mathrm{RR}=0.83,95 \% \mathrm{CI} 0.73,0.94$ ), and with the risk of stroke for individuals who were followed-up for $<10(\mathrm{RR}=0 \cdot 84,95 \% \mathrm{CI} 0 \cdot 72,0 \cdot 91)$. There was a non-linear association between dietary vitamin $\mathrm{E}$ intake and stroke risk $(P=0.0249)$. Omission of any single study did not alter the summary result. In conclusion, this meta-analysis suggests that there is a significant inverse relationship between dietary vitamin $\mathrm{E}$ intake and stroke risk. This meta-analysis provides evidence that a higher dietary vitamin $\mathrm{E}$ intake is associated with a lower stroke risk.

Key words: Vitamin E intake: Stroke risk: Dose-response relationships: Meta-analyses

Stroke is a main cause of death globally and the most common cause of permanent disability in adults in most regions ${ }^{(1)}$. Primary prevention strategies are required to limit the growing burden of stroke. A recent meta-analysis study ${ }^{(2)}$ of randomised controlled trials (RCT) suggested that vitamin E supplementation demonstrated no beneficial effects in prevention of stroke or its subtypes. However, RCT have tended to have short duration, and to use high doses. Thus, the effect of long-term moderate dietary vitamin $\mathrm{E}$ intake on the incidence of stroke needs to be clarified.

Many observational epidemiological studies ${ }^{(3-10)}$ have examined stroke risk related to dietary vitamin $\mathrm{E}$ intake with a few studies ${ }^{(3,9,10)}$ suggesting a protective effect, but others studies ${ }^{(4-8)}$ suggest that there is no effect. However, the results comparing vitamin $\mathrm{E}$ with stroke risk have, thus far, been inconsistent ${ }^{(7,11-14)}$. Given these conflicting results, we conducted this meta-analysis of prospective studies to clarify the associations between vitamin $\mathrm{E}$ intake and risk of stroke.

\section{Methods \\ Literature search and inclusion criteria}

We performed a literature search using PubMed (Medline), Embase, Scopus, the Cochrane library, Web of Knowledge and Google Scholar through to June 2018 using keywords related to vitamin $\mathrm{E}$ intake and cerebrovascular diseases. The keywords were as follows: 'vitamin E' or 'tocopherol'; and 'stroke' or 'cerebrovascular disorders' or 'cerebrovascular disease' or 'cerebrovascular event' or 'cerebrovascular accident' or 'intracranial haemorrhage' or 'brain haemorrhage' or 'transient ischemic attack'; and 'diet' or 'dietary' or 'intake' or 'consumption'. Then, we reviewed the references from the retrieved articles to identify any additional relevant publications. No language restrictions were imposed.

\section{Study selection}

For inclusion, studies had to meet the following criteria: (1) a prospective cohort study or a nested case-control study;

Abbreviations: RCT, randomised controlled trial; RR, relative risk.

* Corresponding author: P. Cheng, email chpfwy@163.com, chengpengfei@jmsu.edu.cn 
(2) evaluated the association between dietary vitamin $\mathrm{E}$ intake and stroke risk; (3) the outcome of interest was stroke and (4) the relative risk (RR) estimates or OR in nested case-control studies with $95 \%$ CI were provided. We excluded RCT, nonhuman experimental studies and non-original research (editorials, reviews or commentaries).

\section{Data extraction}

The following data were extracted: the first author's last name, publication year, study quality, study location, age of participants, stroke events and outcomes (fatal or non-fatal), number of participants, assessment of vitamin $\mathrm{E}$ intake, length of follow up duration, sources of vitamin E, RR and the corresponding CI of stroke for the maximum $v$. the minimum level, and variables that were controlled for in the analysis. The literature search and data extraction were conducted independently by two authors. Disagreements were resolved by discussion or consultation with a third author.

\section{Assessment of methodological quality}

We used the nine-star Newcastle-Ottawa Scale ${ }^{(15)}$ to evaluate the quality of the included studies. Studies were graded as high quality if they achieved a rating of $>7$ stars.

\section{Main and subgroup analyses}

We investigated the association between dietary vitamin $\mathrm{E}$ and cerebrovascular events. We also performed subgroup metaanalyses for vitamin $\mathrm{E}$ intake and stroke risk by type of stroke (ischaemic $v$. haemorrhagic), race (Non-East Asians $v$. East Asians), sex (female $v$. male), sources of vitamin $\mathrm{E}$ intake (foods or supplements), number of participants $(\geq 20000 v$. $<20000)$, BMI adjusted (yes $v$. no).

\section{Statistical analysis}

Log RR of the highest compared with the lowest for cohort studies were weighed by the inverse variance method to obtain pooled RR, and the OR were deemed equivalent to RR. Although three studies ${ }^{(9,10,16)}$ provided the RR of stroke from supplemental vitamin E intake, one of these studies ${ }^{(10)}$ did not provide the available RR and its CI for stroke on the highest supplemental vitamin $\mathrm{E}$ intake. We contacted the authors to request data, but were unsuccessful in making contact with them. Thus, we did not include this study ${ }^{(10)}$ in the metaanalysis of supplemental vitamin E intake and stroke risk.

Between-study heterogeneity was evaluated via the Cochran $Q$ test and $I^{2}$ statistic. Heterogeneity was determined with a significance level of $P<0 \cdot 10$ or an $I^{2}$ statistic $>50 \%$, and we observed the presence of significant heterogeneity. A random effects model was applied when significant heterogeneity was observed; otherwise, a fixed-effect model was used ${ }^{(17,18)}$. We also pooled RR if the individual study reported risk estimates based on stroke subtypes.

We performed a dose-response meta-analysis using the method developed by Greenland \& Longnecker ${ }^{(19)}$ and Orsini et $a l .{ }^{(20)}$ to estimate the trend from the correlated $\log \mathrm{RR}$ across categories of dietary vitamin $\mathrm{E}$ intake. The amount of dietary vitamin $\mathrm{E}$ intake, distributions of cases and person years, and RR and $95 \%$ CI were extracted using this method. The median or mean dietary vitamin $\mathrm{E}$ consumption in each intake category was used as the corresponding consumption dose. For studies that provided dietary vitamin intake using intake ranges, we estimated the midpoint for each category by using the average of the lower and upper bound. When the highest or lowest category was open-ended, we considered the bound to be the same as the closest adjacent category. We estimated a potential non-linear relationship between dietary vitamin $\mathrm{E}$ and stroke risk, using restricted cubic splines with three knots at percentiles 10,50 and $90 \%$ of the distribution ${ }^{(21)}$. A $P$ value for nonlinearity was calculated by making the coefficient of the second spline equal to zero.

We assessed publication bias was assessed using Begg's funnel plot and Egger's test. If publication bias exists, the Begg's funnel plot is asymmetric or the Egger's test $P$ value is $<0.05$. Data analysis was performed using Review Manager 5.3 Software (version 5.3.5; The Nordic Cochrane Centre, The Cochrane Collaboration) and the R 3.2.2 software packages.

\section{Results}

\section{Literature search}

The initial search identified 3165 potential articles. A flow chart showing the details of study selection is shown in Fig. 1. Briefly, nine studies were identified and included in the analysis of the highest compared with the lowest dietary vitamin $\mathrm{E}$ intake and stroke risk. In all, eight studies ${ }^{(3-10)}$ on dietary vitamin $\mathrm{E}$ intake, three studies ${ }^{(9,10,16)}$ on supplemental vitamin $\mathrm{E}$ intake, and two studies $^{(10,16)}$ on total vitamin $\mathrm{E}$ intake were included in the meta-analysis. In all, five studies were awarded seven stars,

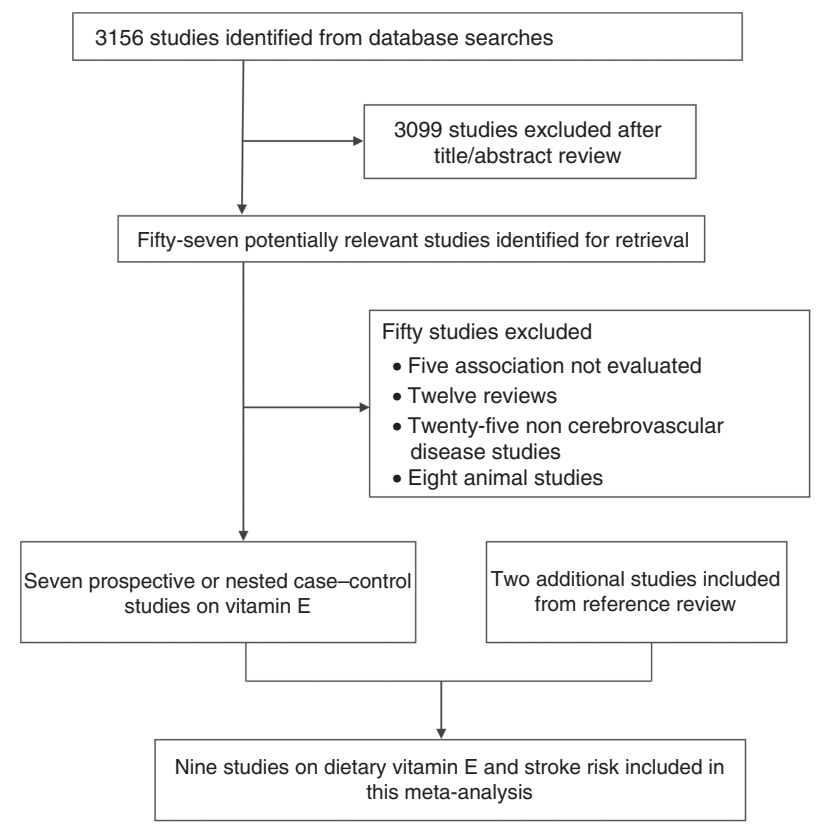

Fig. 1. Flow chart of articles included in this meta-analysis. 
three studies were awarded eight stars, and studies with seven awarded stars were considered as high quality (online Supplementary Table S1).

\section{Study characteristics}

Table 1 shows the characteristics of the nine studies on vitamin $\mathrm{E}$ intake. These studies had a total of 220371 non-overlapping participants and 3284 stroke events. In the studies that reported age, the mean age of the participants ranged from 40 to 99 years. The year of publication of the included studies ranged between 1996 and 2012, spanning 16 years. In all, two studies $^{(10,16)}$ were conducted in the USA, two ${ }^{(5,9)}$ in Netherlands, two ${ }^{(4,7)}$ in Finland, one ${ }^{(3)}$ in Italy, one ${ }^{(8)}$ in China and one $^{(6)}$ in Japan. A total of four studies included males only, four studies included both males and females, one study included females only and the remaining one included a separate result for males or females. The follow-up duration ranged between $6 \cdot 1$ and $16 \cdot 5$ years.

\section{Vitamin E intake and stroke risk}

A total of eight studies ${ }^{(3-10)}$ examined the association of dietary vitamin $\mathrm{E}$ intake with the risk of overall stroke. The summary RR for the high compared with low dietary vitamin $\mathrm{E}$ intake was 0.83 (95\% CI $0.73,0.94)$ (Fig. 2). The effect of total vitamin $\mathrm{E}$ intake on stroke risk was reported in two studies ${ }^{(10,16)}$, and the summary RR for the high- $v$.-low vitamin $\mathrm{E}$ intake was 1.13 (95\% CI 0.84, 1.51), with low heterogeneity ( $P$ heterogeneity $\left.=0.314, I^{2}=1 \cdot 2 \%\right)$. In all, three studies ${ }^{(9,10,16)}$ including 770 stroke patients reported results for supplemental vitamin E intake. However, only two studies ${ }^{(9,16)}$ provided the available RR for supplemental vitamin $\mathrm{E}$ intake and stroke risk. The summary RR for the high- $v$.-low intake was 1.10 (95\% CI $0.85,1.44)$, with no heterogeneity $(P$ heterogeneity $=0.74$, $\left.I^{2}=0.0 \%\right)$.

\section{Dose-response meta-analysis}

In all, six studies ${ }^{(3-6,8,10)}$ were included in the dose-response analysis, with a total of 2837 events among 180231 participants. We found evidence of a non-linear association for dietary vitamin $\mathrm{E}$ intake $(P=0.0249$ for non-linearity) with risk of stroke (online Supplementary Fig. S1).

\section{Subgroup and sensitivity analyses for vitamin E intake}

The subgroup analysis showed that dietary vitamin E intake was associated with reduced risk of stroke for mixed stroke types $(\mathrm{RR}=0.80 ; 95 \%$ CI 0.66, 0.97), for Non-East Asians ( $\mathrm{RR}=0.82$; $95 \%$ CI $0.70,0.95)$, females $(\mathrm{RR}=0.58 ; 95 \%$ CI $0.34,0.99)$, $\geq 20000$ participants in the cohort $(\mathrm{RR}=0.84 ; 95 \%$ CI 0.73 , 0.96), BMI adjusted ( $\mathrm{RR}=0.83 ; 95 \%$ CI $0.73,0.95)$, and $<10$ follow-up years $(\mathrm{RR}=0.84 ; 95 \% \mathrm{CI} 0.72$, 0.91) (Fig. 3). However, dietary vitamin $\mathrm{E}$ intake was not significantly associated with the risk of haemorrhagic stroke ( $R R=1.05 ; 95 \%$ CI 0.49 , $2 \cdot 28$ ). In addition, dietary vitamin $\mathrm{E}$ intake was not associated with stroke risk for East Asians ( $\mathrm{RR}=0.84 ; 95 \%$ CI 0.68, 1.04), males $(\mathrm{RR}=0 \cdot 87 ; 95 \% \mathrm{CI} 0 \cdot 75,1 \cdot 02),<20000$ participants in the cohort $(\mathrm{RR}=0 \cdot 79 ; 95 \% \mathrm{CI} 0 \cdot 61,1 \cdot 03)$, BMI non-adjusted $(\mathrm{RR}=0 \cdot 78$; $95 \%$ CI $0.52,1.17$ ), and $\geq 10$ years follow-up ( $R R=0.79 ; 95 \%$ CI $0.53,1.18$; Fig. 2). In addition, omitting any single study did not remarkably alter the summary risk estimates (RR ranged between 0.80 and 0.84 ; Table 2 ).

\section{Meta-regression}

We used meta-regression analysis to explore the potential sources of heterogeneity. However, stroke type, race, sex, participants, stroke events, BMI, publication year, or years of follow-up was not determined to be the source of heterogeneity in the meta-regression analyses.

\section{Publication bias}

The funnel plot was basically symmetrical, and there was no evidence of publication bias using Egger's test ( $P$ Egger's $=0 \cdot 843$ ) (online Supplementary Fig. S2).

\section{Discussion}

Our meta-analysis supports an inverse association between dietary vitamin $\mathrm{E}$ and stroke risk. Compared with individuals who have less dietary vitamin $\mathrm{E}$ intake, those with high dietary vitamin $\mathrm{E}$ intake have $17 \%$ reduction in the risk of stroke. Total or supplemental vitamin $\mathrm{E}$ intake was not significantly related to a reduced risk of stroke. As a lipid soluble antioxidant, vitamin $\mathrm{E}$ demonstrates its ability to inhibit lipid peroxidation via scavenging reactive oxygen species and to preserve cell membranes ${ }^{(22)}$. In addition, some evidence shows that vitamin $\mathrm{E}$ can improve atherosclerotic plaque stability and vasomotor function, and inhibit platelet aggregation and thrombus formation $^{(23,24)}$.

The role of dietary vitamin $\mathrm{E}$ intake in stroke prevention was found to be inconsistent in the previous studies. Results from four prospective studies ${ }^{(4,5,7,8)}$ agree that vitamin $\mathrm{E}$ has no overall effect on the prevention of stroke or its subtypes (ischaemic or haemorrhagic stroke). Several lines of evidence show that dietary vitamin $\mathrm{E}$ may have a protective effect against stroke mortality in postmenopausal women ${ }^{(10)}$, and on ischaemic smoke in male smokers ${ }^{(9)}$, while another prospective study suggests that a high vitamin $\mathrm{E}$ intake may be positively associated with the risk of haemorrhagic stroke ${ }^{(3)}$.

The subgroup results reveal that dietary vitamin $\mathrm{E}$ tends to be beneficial in prevention of stroke for Non-East Asians (six cohorts) but not for East-Asians (two cohorts), and a possible explanation is that vitamin E intake $(39.45 \mathrm{mg} / \mathrm{d})$ in the China cohort is higher than the amount in all the remaining studies, while vitamin E intake $(6.4 \mathrm{mg} / \mathrm{d}$ for females and $6.6 \mathrm{mg} / \mathrm{d}$ for males) in the Japan cohort is lower than the amount in all the remaining studies. Conversely, the vitamin $\mathrm{E}$ intake (from $10 \cdot 96$ to $24 \mathrm{mg} / \mathrm{d}$ ) tends to be beneficial in preventing stroke among the remaining cohorts. The dietary vitamin $\mathrm{E}$ intake ranges from 6.4 to $39.45 \mathrm{mg} / \mathrm{d}$. It is of interest that the online Supplementary Fig. S1 shows a 'break in the downward slope' associated with 
Table 1. Characteristics of the included prospective studies on vitamin $E$ intake and stroke risk

(Relative risks (RR) and $95 \%$ confidence intervals)

\begin{tabular}{|c|c|c|c|c|c|c|c|c|c|c|c|}
\hline $\begin{array}{l}\text { First author } \\
\text { (year) }\end{array}$ & $\begin{array}{l}\text { Quality score } \\
\text { ( } 0-9,9 \text { is } \\
\text { best) }\end{array}$ & Location & $\begin{array}{c}\text { Age range } \\
\text { (years) }\end{array}$ & Stroke events & Participants & $\begin{array}{l}\text { Vitamin E intake } \\
\text { assessment }\end{array}$ & $\begin{array}{l}\text { Average } \\
\text { follow-up } \\
\text { (years) }\end{array}$ & Sources & $\mathrm{RR}$ & $\begin{array}{l}95 \% \mathrm{Cl} \text {, high } \\
\text { v. low }\end{array}$ & Maximum adjustment \\
\hline Keli (1996) & 8 & Netherlands & $40-59$ & $\begin{array}{l}42 \text { TS (fatal + non- } \\
\text { fatal) }\end{array}$ & $552 \mathrm{M}$ & $\begin{array}{l}\text { Cross-check } \\
\text { dietary history }\end{array}$ & 15 & Foods & 1.64 & $0.54,4.97$ & $\begin{array}{l}\text { Age, SBP, serum cholesterol, } \\
\text { smoking, intakes of fish, } \\
\text { alcohol and energy }\end{array}$ \\
\hline $\begin{array}{l}\text { Ross } \\
\text { (1997) }\end{array}$ & 7 & China & $45-64$ & 245 TS (fatal) & $18244 \mathrm{M}$ & FFQ & 8 & Foods & 0.8 & $0.6,1 \cdot 2$ & $\begin{array}{l}\text { BMI, education, marital } \\
\text { status, smoking, alcohol } \\
\text { and hypertension }\end{array}$ \\
\hline $\begin{array}{r}\text { Ascherio } \\
(1999)\end{array}$ & 8 & USA & $40-75$ & $\begin{array}{l}328 \text { TS, } 210 \text { IS, } 70 \\
\text { HS (fatal + non- } \\
\text { fatal) }\end{array}$ & $43738 \mathrm{M}$ & FFQ & 8 & Supplements & $\begin{array}{l}\text { TS: } 1.25 \\
\text { IS: } 1 \cdot 18 \\
\text { HS: } 1.31 \\
\text { TS: } 1.13 \\
\text { IS: } 1.16 \\
\text { HS: } 1.03\end{array}$ & $\begin{array}{l}\text { TS: } 0.88,1.78 \\
\text { IS: } 0.77,1.82 \\
\text { HS: } 0.62,2.76 \\
\text { TS: } 0.84,1.52 \\
\text { IS: } 0.81,1.67 \\
\text { HS: } 0.52,2.03\end{array}$ & $\begin{array}{l}\text { Age, calendar time, smoking, } \\
\text { energy, alcohol, } \\
\text { hypertension, parental } \\
\text { history of MI, profession, } \\
\text { BMl and physical activity }\end{array}$ \\
\hline $\begin{array}{r}\text { Hirvonen } \\
(2000)\end{array}$ & 8 & Finland & $50-69$ & $\begin{array}{l}736 \mathrm{IS}, 95 \mathrm{ICH}, 83 \\
\text { SAH (fatal + non- } \\
\text { fatal) }\end{array}$ & $26593 \mathrm{M}$ & FFQ & $6 \cdot 1$ & Foods & $\begin{array}{l}\text { IS: } 0.86 \\
\text { SAH: } 0.81 \\
\text { ICH: } 0.64\end{array}$ & $\begin{array}{l}\text { IS: } 0 \cdot 70,1 \cdot 06 \\
\text { SAH: } 0.44, \\
1.50 \\
\text { ICH: } 0.36,1 \cdot 15\end{array}$ & $\begin{array}{l}\text { Age, supplementation group, } \\
\text { SBP, DBP, serum total } \\
\text { cholesterol and HDL- } \\
\text { cholesterol, BMI, height, } \\
\text { smoking, history of } \\
\text { diabetes or CHD, alcohol } \\
\text { intake and education }\end{array}$ \\
\hline $\begin{array}{l}\text { Yochum } \\
\text { (2000) }\end{array}$ & 9 & USA & $55-69$ & 215 TS (fatal) & $34492 \mathrm{~F}$ & FFQ & 11 & $\begin{array}{l}\text { Total } \\
\text { Foods } \\
\text { Supplements }\end{array}$ & $\begin{array}{l}0.91 \\
0.40 \\
1.21\end{array}$ & $\begin{array}{l}0.55,1.52 \\
0.20,0.80 \\
0.38,1.19\end{array}$ & $\begin{array}{l}\text { Age, BMI, waist:hip ratio, } \\
\text { hypertension, diabetes, } \\
\text { estrogen replacement } \\
\text { therapy, education, marital } \\
\text { status, smoking, physical } \\
\text { activity, intakes of total } \\
\text { energy, cholesterol, } \\
\text { alcohol, saturated fat, fish, } \\
\text { vitamin E, carotenoids, } \\
\text { dietary fibre and whole } \\
\text { grains }\end{array}$ \\
\hline $\begin{array}{l}\text { Vokó } \\
\text { (2003) }\end{array}$ & 8 & Netherlands & $67 \cdot 6$ & $\begin{array}{l}227 \text { IS (fatal + non- } \\
\text { fatal) }\end{array}$ & $\begin{array}{l}5197 \text { mixed } \\
M \text { and } F\end{array}$ & $\mathrm{FFQ}$ & 6.4 & $\begin{array}{l}\text { Foods } \\
\text { Supplements }\end{array}$ & $\begin{array}{l}0.72 \\
1.01\end{array}$ & $\begin{array}{l}0.42,1.25 \\
0.56,1.83\end{array}$ & $\begin{array}{l}\text { Age, sex, total energy intake, } \\
\text { smoking, hypertension, } \\
\text { diabetes mellitus, history } \\
\text { of CHD, transient } \\
\text { ischaemic attacks, and, in } \\
\text { case of vitamin E, PUFA } \\
\text { intake }\end{array}$ \\
\hline $\begin{array}{l}\text { Marniemi } \\
(2005)\end{array}$ & 8 & Finland & $65-99$ & $\begin{array}{l}70 \text { TS (fatal + non- } \\
\text { fatal) }\end{array}$ & $\begin{array}{l}755 \text { mixed } M \\
\text { and } F\end{array}$ & $\mathrm{FFQ}$ & 10 & Foods & 0.663 & $0.32,1.37$ & $\begin{array}{l}\text { Age, sex, smoking, functional } \\
\text { capacity and weight- } \\
\text { adjusted energy intake }\end{array}$ \\
\hline $\begin{array}{l}\text { Del Rio } \\
\text { (2011) }\end{array}$ & 8 & Italy & $44-61$ & $\begin{array}{l}194 \text { TS, } 112 \text { IS, } 48 \\
\text { HS (fatal + non- } \\
\text { fatal) }\end{array}$ & $\begin{array}{l}41620 \\
\text { mixed M } \\
\text { and } F\end{array}$ & $\mathrm{FFQ}$ & 7.9 & Foods & $\begin{array}{l}\text { TS: } 1.08 \\
\text { IS: } 0.76 \\
\text { HS: } 2.94\end{array}$ & $\begin{array}{l}\text { TS: } 0.68,1 \cdot 72 \\
\text { IS: } 0.40,1.42 \\
\text { HS: } 1 \cdot 13,7.62\end{array}$ & $\begin{array}{l}\text { Age, center, sex, } \\
\text { hypertension, smoking, } \\
\text { education, energy intake, } \\
\text { alcohol, waist } \\
\text { circumference, obesity } \\
\text { and physical activity. } \\
\text { Participants being treated } \\
\text { for hyperlipidaemia or } \\
\text { diabetes were excluded }\end{array}$ \\
\hline
\end{tabular}


RR at

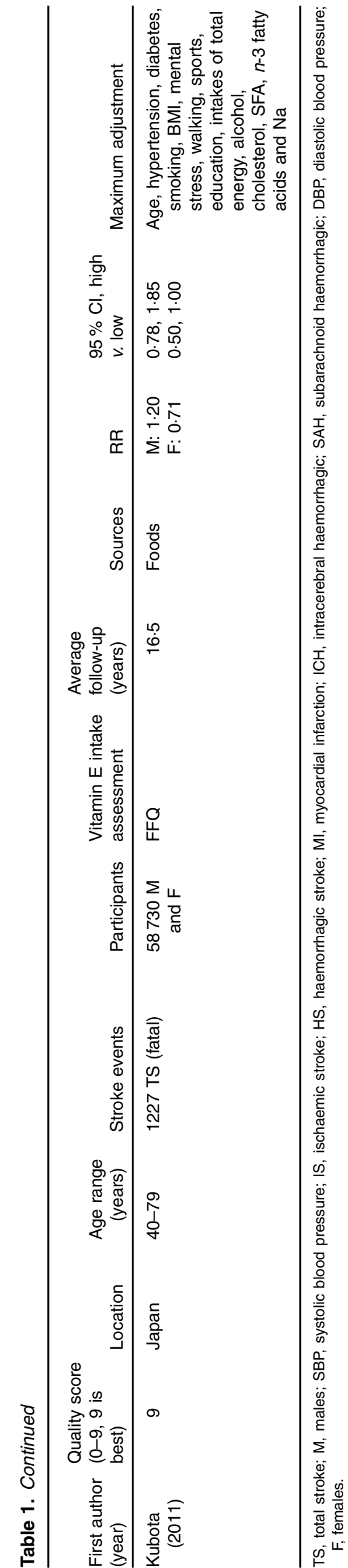

approximately $15 \mathrm{mg} / \mathrm{d}$, this is the same value as the recommended intake in the USA ${ }^{(25)}$. Thus, based on this evidence and the results of our meta-analysis, dietary vitamin $\mathrm{E}$ intake between 15 and $39.45 \mathrm{mg} / \mathrm{d}$ appears to be beneficial in prevention of stroke. The proportion of participants in the population who eat insufficient vitamin $\mathrm{E}$ is approximately $75 \%$. Although nine studies involving 3284 events and 220371 participants were included in the final analyses, the statistical power was still limited. Therefore, the recommended daily allowances for vitamin $\mathrm{E}$ in prevention of stroke needs to be further addressed.

Dietary vitamin E tends to be beneficial in the prevention of stroke for females but not for males. However, the biological mechanisms are not clear. When the analysis was performed in cohorts with a larger number of participants $(\geq 20000)$, the beneficial effect of vitamin $\mathrm{E}$ persisted. BMI is a factor affecting the incidence of stroke $\mathrm{e}^{(26,27)}$, and when the analysis was adjusted for this confounder, the beneficial effects of dietary vitamin $\mathrm{E}$ persisted. Based on our results, dietary vitamin $\mathrm{E}$ intake is associated with a reduced risk of stroke for follow-up $<10$ years but not for follow-up $>10$ years. Thus, there may be an optimal time window for dietary vitamin $\mathrm{E}$ intake in the prevention of stroke, this may be explained by the inconsistencies of a wider range for studies with follow-up $\geq 10$ years (range, 10-16.5 years) compared with studies with follow-up $<10$ years (range, $6 \cdot 1-8$ years). There was low heterogeneity ( $17 \%$ ) between the included studies. However, the sources of heterogeneity could not be determined using meta-regression analyses and subgroup meta-analyses.

Our findings, however, are inconsistent with those of the previous meta-analysis $^{(2)}$ of RCT, which suggested that vitamins E intake is not associated with stroke risk. In addition, the use of vitamin E supplements in RCT should not be considered to be equivalent to the intake of olive oils, nuts and vegetables in prospective cohort studies, because these contain various other nutrients. For example, olive oil is rich in MUFA, which is inversely associated with haemorrhagic stroke ${ }^{(28)}$. Nuts have a low SFA content (4-16\%) and high MUFA content, as well as a variable amount of PUFA, such as linolenic acid ${ }^{(29)}$, which is inversely associated with ischaemic stroke, possibly through potential mechanisms of decreased blood pressure, reduced platelet aggregation, and enhanced deformability of erythrocyte cells ${ }^{(30)}$. Vegetables are rich sources of $\mathrm{K}$ and antioxidants (such as vitamin $\mathrm{C}$ ), which are significantly associated with lower rates of stroke ${ }^{(31,32)}$. Based on the included studies, the main dietary sources of vitamin $\mathrm{E}$ are derived from consumption of fruits, nuts, vegetable oils, and vegetables, and the proportion of vitamin $\mathrm{E}$ in each food varies. Therefore, our results suggest that the beneficial effects of vitamin $\mathrm{E}$ on the risk of stroke might be obtained from a combination of a higher proportion of vitamin $\mathrm{E}$ and a specific proportion of other dietary components.

There are several limitations in the current study. First, heterogeneity is present among the included studies, but the metaregression analyses did not reveal any source of heterogeneity. Second, the included studies used both the cross-check dietary history method and the FFQ to assess dietary vitamin E intake, and thus, the estimated consumption of vitamin E might not be accurate. However, vitamin $\mathrm{E}$ intake was cross checked or 


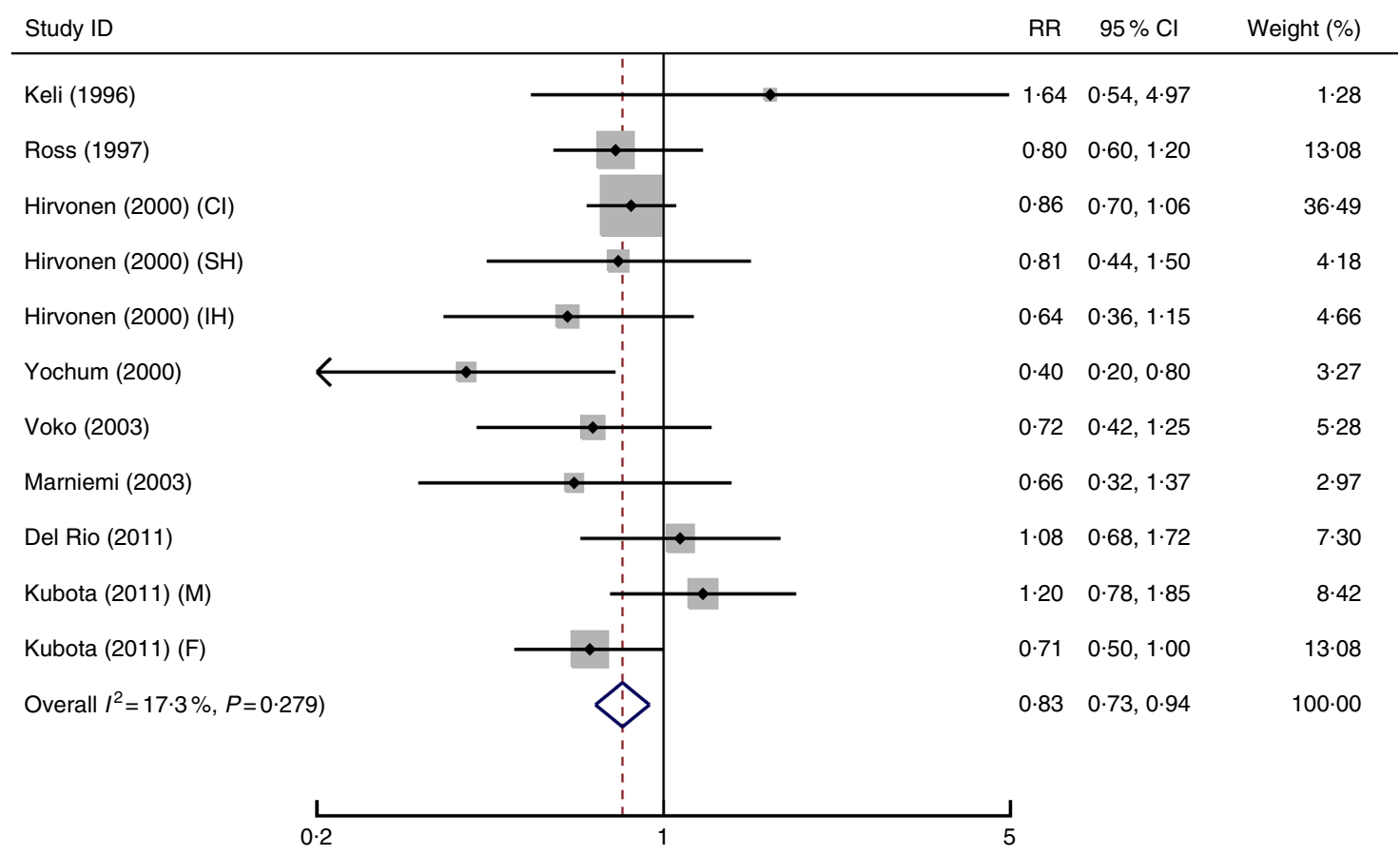

Fig. 2. Meta-analysis of dietary vitamin $\mathrm{E}$ intake and risk of stroke. $\mathrm{Cl}$, cerebral infarction; $\mathrm{SH}$, subarachnoid haemorrhage; $\mathrm{IH}$, intracerebral haemorrhage; $\mathrm{M}$, males; $\mathrm{F}$, females.

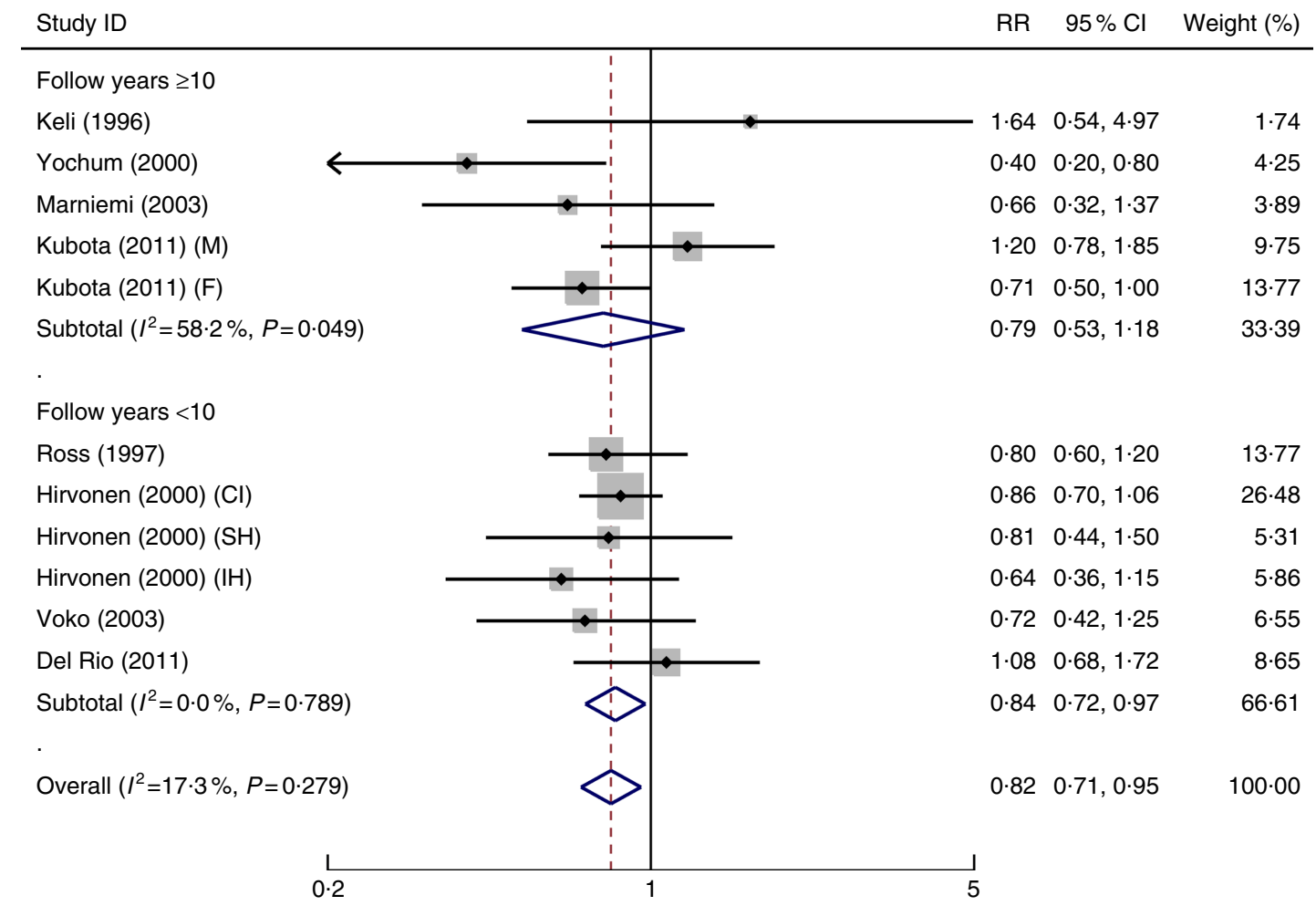

Fig. 3. Meta-analysis of vitamin $\mathrm{E}$ intake and stroke risk for follow-up years subgroups. $\mathrm{M}$, males; $\mathrm{F}$, females; $\mathrm{Cl}$, cerebral infarction; $\mathrm{SH}$, subarachnoid haemorrhage; $\mathrm{IH}$, intracerebral haemorrhage.

validated in most of the included studies. Moreover, although observational studies adjusted for several confounders, residual confounding is still an issue, and confounding factors in each study may not be consistent. However, adjustment for major confounding factors should reduce the potential bias. Third, the results of subgroup analyses may not be robust because of the limited number of studies included. Finally, most of the studies were from America and Europe, and few studies were 
Table 2. Subgroup analyses of dietary vitamin $E$ intake and stroke, high $v$. low intake (Relative risks (RR) and $95 \%$ confidence intervals)

\begin{tabular}{|c|c|c|c|c|c|}
\hline Outcome & Studies & $\mathrm{RR}$ & $95 \% \mathrm{Cl}$ & $P$ for heterogeneity & $P$ for heterogeneity \\
\hline Total stroke & 8 & 0.83 & $0.73,0.94$ & $17 \cdot 3$ & 0.279 \\
\hline \multicolumn{6}{|l|}{ Stroke type } \\
\hline Ischaemic & 3 & 0.83 & $0.69,1.00$ & 0 & 0.800 \\
\hline Haemorrhagic & 2 & 1.05 & $0.49,2.28$ & $72 \cdot 8$ & $0.025^{*}$ \\
\hline Mixed & 5 & 0.80 & $0.66,0.97$ & $47 \cdot 7$ & 0.089 \\
\hline \multicolumn{6}{|l|}{ Race } \\
\hline Non-East Asians & 6 & 0.82 & $0.70,0.95$ & $17 \cdot 0$ & 0.296 \\
\hline East Asians & 2 & 0.84 & $0.68,1.04$ & 44.4 & 0.165 \\
\hline \multicolumn{6}{|l|}{ Sex } \\
\hline Female & 2 & 0.58 & $0.34,0.99$ & 52.5 & 0.147 \\
\hline Male & 4 & 0.87 & $0.75,1.02$ & 0 & 0.448 \\
\hline \multicolumn{6}{|l|}{ BMI-adjusted } \\
\hline Yes & 5 & 0.83 & $0.73,0.95$ & $30 \cdot 1$ & 0.188 \\
\hline No & 3 & 0.78 & $0.52,1.17$ & 0.4 & 0.366 \\
\hline \multicolumn{6}{|l|}{ Participants } \\
\hline$\geq 20000$ & 4 & 0.84 & $0.73,0.96$ & 39.7 & 0.127 \\
\hline$<20000$ & 4 & 0.79 & $0.61,1.03$ & 0 & 0.569 \\
\hline \multicolumn{6}{|l|}{ Follow years } \\
\hline$\geq 10$ & 4 & 0.79 & $0.53,1.18$ & 58.2 & $0.049^{*}$ \\
\hline$<10$ & 4 & 0.84 & $0.72,0.97$ & 0 & 0.789 \\
\hline
\end{tabular}

${ }^{*} P<0.05$, statistical difference.

conducted in East Asia. Therefore, more studies need to be included from other parts of the world such as Asia.

In conclusion, this meta-analysis provides evidence that a higher dietary vitamin $\mathrm{E}$ intake is associated with a reduced risk of stroke.

\section{Acknowledgements}

The authors thank Jodi Smith, PhD, from Liwen Bianji, Edanz Editing China (www.liwenbianji.cn/ac), for editing the English text of a draft of this manuscript.

This work was supported by the Natural Science Foundation of Heilongjiang Province (grant no. H2016087), Natural Science Program of Health and Family Planning Commission of Heilongjiang Province (grant no. 2016-280), Natural Science Program of Jiamusi University (grant no. JMSURCGG2016-004).

The authors' contributions are as follows: P. C. and L. W. contributed to the study design, literature search, data extraction and data analyses; S. N., Z. L. and H. L. conducted the literature search; S. C. and J. Z. extracted the data and conducted the statistical analyses; P. C. and L. W. wrote the first draft of the manuscript and edited the manuscript. All authors read and approved the final manuscript.

None of the authors has any conflicts of interest to report.

\section{Supplementary material}

For supplementary material/s referred to in this article, please visit https://doi.org/10.1017/S0007114518002647

\section{References}

1. Go AS, Mozaffarian D, Roger VL, et al. (2014) Heart disease and stroke statistics-2014 update: a report from the American Heart Association. Circulation 129, e28.
2. Myung S-K, Ju W, Cho B, et al. (2013) Efficacy of vitamin and antioxidant supplements in prevention of cardiovascular disease: systematic review and meta-analysis of randomised controlled trials. BMJ 346, f10.

3. Del Rio D, Agnoli C, Pellegrini N, et al. (2011) Total antioxidant capacity of the diet is associated with lower risk of ischemic stroke in a large Italian cohort. J Nutr 141, 118-123.

4. Hirvonen T, Virtamo J, Korhonen P, et al. (2000) Intake of flavonoids, carotenoids, vitamins $\mathrm{C}$ and $\mathrm{E}$, and risk of stroke in male smokers. Stroke 31, 2301-2306.

5. Keli SO, Hertog MG, Feskens EJ, et al. (1996) Dietary flavonoids, antioxidant vitamins, and incidence of stroke: the Zutphen study. Arch Intern Med 156, 637-642.

6. Kubota Y, Iso H, Date C, et al. (2011) Dietary intakes of antioxidant vitamins and mortality from cardiovascular disease the Japan Collaborative Cohort (JACC) study. Stroke $\mathbf{4 2 ,}$ $1665-1672$

7. Marniemi J, Alanen E, Impivaara O, et al. (2005) Dietary and serum vitamins and minerals as predictors of myocardial infarction and stroke in elderly subjects. Nutr Metab Cardiovasc 15, 188-197.

8. Ross RK, Yuan J-M, Henderson BE, et al. (1997) Prospective evaluation of dietary and other predictors of fatal stroke in Shanghai, China. Circulation 96, 50-55.

9. Voko Z, Hollander M, Hofman A, et al. (2003) Dietary antioxidants and the risk of ischemic stroke: the Rotterdam Study. Neurology 61, 1273-1275.

10. Yochum LA, Folsom AR \& Kushi LH (2000) Intake of antioxidant vitamins and risk of death from stroke in postmenopausal women. Am J Clin Nutr 72, 476-483.

11. Hak AE, Ma J, Powell CB, et al. (2004) Prospective study of plasma carotenoids and tocopherols in relation to risk of ischemic stroke. Stroke 35, 1584-1588.

12. Leppälä JM, Virtamo J, Fogelholm R, et al. (1999) Different risk factors for different stroke subtypes association of blood pressure, cholesterol, and antioxidants. Stroke 30, 2535-2540.

13. Nagao M, Moriyama Y, Yamagishi K, et al. (2012) Relation of serum $\alpha$-and $\gamma$-tocopherol levels to cardiovascular diseaserelated mortality among Japanese men and women. J Epidemiol 22, 402-410. 
14. Wright ME, Lawson KA, Weinstein SJ, et al. (2006) Higher baseline serum concentrations of vitamin $\mathrm{E}$ are associated with lower total and cause-specific mortality in the AlphaTocopherol, Beta-Carotene Cancer Prevention Study. Am J Clin Nutr 84, 1200-1207.

15. Stang A (2010) Critical evaluation of the Newcastle-Ottawa scale for the assessment of the quality of nonrandomized studies in meta-analyses. Eur J Epidemiol 25, 603-605.

16. Ascherio A, Rimm EB, Hernán MA, et al. (1999) Relation of consumption of vitamin $\mathrm{E}$, vitamin $\mathrm{C}$, and carotenoids to risk for stroke among men in the United States. Ann Intern Med 130, 963-970.

17. Higgins J \& Thompson SG (2002) Quantifying heterogeneity in a meta-analysis. Stat Med 21, 1539-1558.

18. Lau J, Ioannidis JP \& Schmid CH (1997) Quantitative synthesis in systematic reviews. Ann Intern Med 127, 820-826.

19. Greenland S \& Longnecker MP (1992) Methods for trend estimation from summarized dose-response data, with applications to meta-analysis. Am J Epidemiol 135, 1301-1309.

20. Orsini N, Bellocco R \& Greenland S (2006) Generalized least squares for trend estimation of summarized doseresponse data. Stata J 6, 40-57.

21. Orsini N, Li R, Wolk A, et al. (2012) Meta-analysis for linear and nonlinear dose-response relations: examples, an evaluation of approximations, and software. Am J Epidemiol 175, 66-73.

22. Clarke MW, Burnett JR \& Croft KD (2008) Vitamin E in human health and disease. Crit Rev Clin Lab Sci 45, 417-450.

23. Saldeen T, Li D \& Mehta JL (1999) Differential effects of $\alpha$-and $\gamma$-tocopherol on low-density lipoprotein oxidation, superoxide activity, platelet aggregation and arterial thrombogenesis. J Am Coll Cardiol 34, 1208-1215.

24. Liu M, Wallmon A, Olsson-Mortlock C, et al. (2003) Mixed tocopherols inhibit platelet aggregation in humans: potential mechanisms. Am J Clin Nutr 77, 700-706.

25. Council NR \& Council NR (2000) Dietary Reference Intakes for Vitamin C, Vitamin E, Selenium, and Carotenoids. Washington, DC: National Academies Press.

26. Strazzullo P, D'Elia L, Cairella G, et al. (2010) Excess body weight and incidence of stroke meta-analysis of prospective studies with 2 million participants. Stroke 41, e418-e426.

27. Cheng P, Huang W, Bai S, et al. (2015) BMI affects the relationship between long chain $n$-3 polyunsaturated fatty acid intake and stroke risk: a meta-analysis. Sci Rep 5, 14161.

28. Cheng P, Wang J \& Shao W (2016) Monounsaturated fatty acid intake and stroke risk: a meta-analysis of prospective cohort studies. J Stroke Cerebrovasc Dis 25, 1326-1334.

29. Grosso G, Yang J, Marventano S, et al. (2015) Nut consumption on all-cause, cardiovascular, and cancer mortality risk: a systematic review and meta-analysis of epidemiologic studies. Am J Clin Nutr 101, 783-793.

30. Iso H, Sato S, Umemura U, et al. (2002) Linoleic acid, other fatty acids, and the risk of stroke. Stroke 33, 2086-2093.

31. D'Elia L, Barba G, Cappuccio FP, et al. (2011) Potassium intake, stroke, and cardiovascular disease: a meta-analysis of prospective studies. J Am Coll Cardiol 57, 1210-1219.

32. Chen G-C, Lu D-B, Pang Z, et al. (2013) Vitamin C intake, circulating vitamin $\mathrm{C}$ and risk of stroke: a meta-analysis of prospective studies. J Am Heart Assoc 2, e000329. 